\title{
A situação de violência doméstica de gênero na atenção primária à saúde
}

\author{
The violence against woman in primary health care
}

\author{
Camila Faria Pierotti ${ }^{1}$, Ana Flávia Pires Lucas d'Oliveira ${ }^{2}$, Maria Fernanda Terra ${ }^{3}$
}

\begin{abstract}
Resumo
A violência contra as mulheres é resultante das desigualdades de gênero na sociedade. A Atenção Primária à Saúde (APS) é intensamente procurada pelas mulheres em situação de violência, mas nem sempre as respostas recebidas contribuem para tornar a Rota menos crítica no enfrentamento da violência. Este estudo buscou identificar as Rotas Criticas das mulheres, a partir da APS. Trata-se de um estudo qualitativo, a partir da análise de 5 entrevistas com mulheres indicadas pela APS em situação de violência. Os resultados mostram que a violência doméstica de gênero é reconhecida nos serviços de APS e as mulheres se sentem acolhidas para falarem sobre o problema nessas instituições, porém, a APS aparentemente, se mostra desarticulada dos demais serviços da rede.
\end{abstract}

Descritores: Identidade de gênero, Violência contra a mulher, Atenção primária à saúde

\begin{abstract}
Violence against women is the result of gender inequalities in society. Primary Health Care (APS) is intensely sought after by women in situations of violence, but the responses do not always contribute to making the route less critical in coping with violence. This study aimed to identify the Critical Routes of women, starting from APS. This is a qualitative study, based on the analysis of 5 interviews with
\end{abstract}

1. Enfermeira Residente - Saúde Coletiva e Atenção Primária da Universidade de São Paulo

2. Docente da Universidade de São Paulo. Faculdade de Medicina. Departamento de Medicina Preventiva

3. Professora Instrutora da Faculdade de Medicina da Faculdade de Ciências Médicas da Santa Casa de São Paulo - Curso de Graduação em Enfermagem

Trabalho realizado: Faculdade de Medicina da Universidade de São Paulo. Faculdade de Ciências Médicas da Santa Casa de São Paulo

Endereço para correspondência: Maria Fernanda Terra. Rua Dr. Cesario Motta Jr, 61 - $9^{\circ}$ andar - Vila Buarque, 01221-020 - São Paulo-SP-Brasil.E-mail:mfterra@gmail.com women indicated by the APS in situations of violence. The results show that domestic gender violence is recognized in APS services and women feel welcome to talk about the problem in these institutions, but apparently APS is disjointed from other network services.

Keywords: Gender identity, Violence against women, Primary health care

\section{Introdução}

Gênero é um importante marcador de desigualdade social entre os homens e as mulheres. $\operatorname{Scott}^{(1)}$ apresenta esta categoria como diferenças corporais marcadas por desigualdades sociais e permeadas por relações de poder. É construído socialmente, culturalmente e historicamente na sociedade. As desigualdades de gênero são base de situações de violência sofridas por mulheres pelo fato de serem mulheres, que acontecem no espaço público, mas também e principalmente no espaço doméstico, ocorrendo em alta magnitude ${ }^{(2)}$. Tais violações são classificadas como violência doméstica de gênero e que, na maioria das vezes, são perpetradas pelos parceiros íntimos ${ }^{(3)}$

A violência contra as mulheres não é uma patologia, mas tem grande impacto sobre a saúde daquelas que vivem sob essa condição. Mulheres em situação de violência doméstica de gênero buscam mais intensamente os serviços de saúde com queixas vagas, de ordem reprodutiva e/ou de saúde mental, além de relatos de abortamentos decorrentes da violência e de tentativas de suicídio mais frequente em relação às mulheres que não viveram situações de violência ${ }^{(3)}$.

Os serviços da Atenção Primária à Saúde (APS) são considerados a porta de entrada para o Sistema Único de Saúde (SUS), e por isso são reconhecidos como potentes para visibilizarem a violência de gênero e acolherem as mulheres em situação de violência. As Unidades Básicas de Saúde (UBS) se localizam dentro da comunidade, são responsáveis por resolverem $80 \%$ das demandas da população do território e, a partir do vínculo, cuidar de forma integral e longitudinal das pessoas e das famílias da comunidade ${ }^{(4)}$. Nesse 
sentido, reconhecer a situação de violência sofrida pelas mulheres faz-se fundamental para a prestação de uma assistência integral e de qualidade.

$\mathrm{O}$ atendimento integral e de qualidade foi uma cobrança do movimento de mulheres e teve grande avanço na década de 80 com a implantação do Programa de Atenção integral à Saúde da Mulher (PAISM), apesar de posterior retrocesso. O PAISM deu ênfase à assistência às mulheres numa perspectiva da politização do cuidado ao incluir a discussão acerca das relações de poder no interior dos serviços de saúde, e tematizar as relações de gênero, classe e etnia ${ }^{(3)}$.

Em relação à assistência em violência, os serviços iniciais criados foram as Delegacias de Defesa da Mulher (DDM) e as casas/abrigos ${ }^{(3)}$. Em 2004, a Política Nacional de Assistência Integral à Saúde da Mulher (PNAISM), introduziu a assistência às mulheres em situação de violência doméstica e sexual e o combate do problema como questões prioritárias em saúde ${ }^{(5)}$. A promulgação da Lei Maria da Penha, Lei $n^{\circ}: 11.340 / 2006$, foi um importante marco para a proteção das mulheres, para a estruturação da rede de enfrentamento à violência contra as mulheres e da rede de atendimento às mulheres em situação de violência.

A Lei normatiza que o trabalho da rede seja articulado entre os diferentes setores, dentre eles a segurança pública, a justiça, a educação, a assistência social, a saúde, e outros ${ }^{(3)}$. Apesar dos esforços, a existência dos serviços da rede tem tido muitas dificuldades para apoiar as mulheres a superarem a situação de violência doméstica sofrida. Essa trajetória, na maioria das vezes, é marcada por desencontros, obstáculos, falta de apoio, julgamentos e por tais dificuldades, foi nominada de Rota Crítica ${ }^{(6-7)}$. As mulheres iniciam a Rota no momento em que decidem falar sobre a violência sofrida. Esse primeiro contato, na maioria das vezes, é feito com amigos ou familiares (rede informal) e, posteriormente, com os serviços da rede ${ }^{(6)}$.

O objetivo desse artigo foi identificar as Rotas Críticas das mulheres no enfrentamento da violência, a partir da assistência ofertada na APS.

\section{Método}

Pesquisa de natureza qualitativa, de característica exploratória e tem por escopo ser um estudo de campo. O conteúdo das entrevistadas foi analisado por meio do método da análise de conteúdo ${ }^{8}$. Foram analisadas 5 entrevistas de mulheres em situação de violência que citaram a Atenção Primária à Saúde como espaço importante para receberem suporte para o enfrentamento da violência. Essas 5 entrevistas foram selecionadas dentre as 20 entrevistas advindas da pesquisa maior intitulada "Atenção primária à saúde e o cuidado integral em violência doméstica de gênero: estudo sobre a Rota Crítica das mulheres e crianças e redes intersetoriais". Essa pesquisa maior foi coordenada pelas professoras doutoras Ana Flávia Pires Lucas d'Oliveira e Lilia Blima Schraiber, ambas do Departamento de Medicina Preventiva da Faculdade de Medicina da Universidade de São Paulo (USP). A seleção das entrevistas para este estudo se baseou na identificação do serviço de APS como suporte às mulheres no enfrentamento da violência doméstica de gênero. As entrevistas com as mulheres em situação de violência doméstica de gênero foram realizadas em Unidades Básicas de Saúde (UBS) da região Oeste do município de São Paulo, no período de outubro de 2013 a fevereiro de 2015. Estas foram gravadas, transcritas e posteriormente analisadas. $\mathrm{O}$ projeto foi aprovado nos Comitês de Ética da Secretaria de Saúde do Município de São Paulo e da Faculdade de Medicina da USP, sob protocolo ${ }^{\circ} 234 / 13$. Todas as mulheres foram orientadas sobre a pesquisa, sobre a possibilidade de desistirem da participação da pesquisa, foram orientadas sobre o sigilo e elas leram ou foi lido a elas o Termo de Consentimento Livre e Esclarecido.

As cinco mulheres foram nominadas de Tulipa, Margarida, Rosa, Hortênsia e Orquídea. As entrevistas foram analisadas a partir da técnica de Análise de Conteúdo proposta por Bardin ${ }^{(8)}$. Os resultados foram organizados a partir das categorias temáticas: Concepções sobre a violência sofrida (o que é violência, quais as situações vividas que são consideradas violência, quando começou a violência, motivo para permanecer no casamento, obstáculos e apoios); as dificuldades das mulheres e as redes buscadas para enfrentar a violência e as Respostas dos serviços da APS às mulheres.

\section{Resultados e discussão}

As informações individualizadas das mulheres estão descritas no quadro 1 .

Apesar de a amostra ser composta por apenas 5 entrevistas com mulheres, o estudo mostra que a violência psicológica foi a $1^{a}$ queixa relatada por elas, seguida da violência física, sexual e aparece a violência patrimonial, informações diferentes do que foi mostrado por Schraiber, D'Oliveira, 2002 ${ }^{(9)}$, quando $78,8 \%$ das mulheres relataram violência física, 39,7\% violência psicológica e $24,2 \%$, violência sexual e não houve relato da violência patrimonial.

O segundo quadro mostra a $1^{a}$ instituição ou pessoa buscada pelas mulheres para ajudar no enfrentamento da violência.

Como relatado pela literatura ${ }^{(6)}$, aqui as mulheres também buscaram as pessoas próximas para falarem do problema da violência e após esse primeiro suporte 
Quadro 1

Caracterização das mulheres entrevistadas nas regiões da Coordenadoria Oeste do Município de São Paulo. São Paulo, 2015.

\begin{tabular}{|c|c|c|c|c|c|c|}
\hline Mulher & Idade & Cor & Anos de estudo & Ocupação & Tipo de violência & $\begin{array}{l}\text { Tempo de } \\
\text { violência }\end{array}$ \\
\hline Tulipa & 26 & Negra & 11 & Dona de casa & $\begin{array}{c}\text { Física, } \\
\text { psicológica, } \\
\text { sexual e } \\
\text { patrimonial }\end{array}$ & 5 anos \\
\hline Margarida & 29 & Parda & 11 & Diarista & $\begin{array}{c}\text { Psicológica e } \\
\text { física }\end{array}$ & 6 anos \\
\hline Rosa & 36 & Parda & 8 & Diarista & $\begin{array}{c}\text { Física, } \\
\text { psicológica e } \\
\text { sexual }\end{array}$ & 15 anos \\
\hline Hortênsia & 43 & Negra & 8 & Doméstica & $\begin{array}{l}\text { Psicológica e } \\
\text { física }\end{array}$ & 9 anos \\
\hline Orquídea & 56 & Negra & 4 & Dona de casa & $\begin{array}{c}\text { Psicológica e } \\
\text { patrimonial }\end{array}$ & 5 anos \\
\hline
\end{tabular}

\section{Quadro 2}

Instituições e/ou pessoas buscadas pelas mulheres entrevistadas em ordem cronológica nas regiões das Coordenadorias Oeste do Município de São Paulo. São Paulo, 2015.

\begin{tabular}{|c|c|c|c|c|c|}
\hline & Tulipa & Margarida & Rosa & Hortênsia & Orquídea \\
\hline $1^{\mathrm{o}}$ & Mãe/Primo & Familiares & Amiga/Mãe & UBS & $\begin{array}{l}\text { Filhos / } \\
\text { vizinhos }\end{array}$ \\
\hline $2^{\circ}$ & UBS & UBS & DDM & $\begin{array}{c}\text { Defensoria } \\
\text { Pública }\end{array}$ & UBS \\
\hline $3^{\circ}$ & -- & $\begin{array}{c}\text { Delegacia de defesa da } \\
\text { Mulher (DDM) }\end{array}$ & UBS & $\begin{array}{l}\text { Casa de } \\
\text { referência }\end{array}$ & -- \\
\hline $4^{\mathrm{o}}$ & -- & Defensoria pública & Centro espírita & -- & -- \\
\hline
\end{tabular}

positivo, seguiram no enfrentamento do problema a partir da busca de instituições formais para receberem apoio.

\section{Concepções sobre a violência sofrida}

As 5 mulheres entrevistadas compreendiam a violência que sofriam e destacavam que as humilhações e os xingamentos as machucavam muito mais do que agressões físicas que sofriam. Pesquisas ${ }^{(10-11)}$ corroboram essa informação, de que a violência psicológica é muito mais constrangedora e dolorosa do que as outras violências, por deixarem feridas que não cicatrizam. Uma das mulheres referiu:

Porque tanto faz agredir com palavra ou com pancada, tá fazendo tudo do mesmo jeito. (Tulipa)

Então, não me dá valor, é uma pessoa que não me dá valor. Não sabe o meu respeito. Eu não concordo... muita coisa que ele fala, me maltrata de palavras...
- ah, mas... eu nem sei se esse filho é meu... não sei o que..., mas você pediu, você ficou encima, era o seu sonho... e hoje tem horas que duvida que é seu? Então, não tenho muito... violência é quando começa a me maltratar, acusar - vocêfez isso, você fez aquilo. (Margarida)

Me xingava, falava para o meu filho que eu era vagabunda... que eu não valia nada, que ia falar com o meu pai. Quando eu casei com ele eu era virgem, né?, ele falou que ia falar para meu pai que eu não era virgem, coisa nenhuma, que ia me entregar. Que só não me entregou porque ele que não quis... Isso tudo, ameaça para cima de mim... para a minha pessoa... para ver se eu não separava dele, entendeu? Isso aqui que estou te falando... não existia palavra de separação entre nós dois. Foi quando ele ficou preso que ele ficou com medo de eu pedir a separação... aí ele começou com tudo isso. (Hortênsia)

Sofrer violência perpetrada por uma pessoa ínti- 
ma, escolhida para compor a família, é uma situação complexa e sensível e por isso muitas mulheres não usam o termo violência para nominar esse sofrimento, termo esse usado para referenciar os episódios de violência ocorridos fora do ambiente familiar ${ }^{(12)}$, e que nesse estudo aparece como falta de respeito, desconfiança, etc. No trecho que segue abaixo fica clara essa dificuldade:

O que você acha disso que você viveu? Que nome você dá para tudo isso que você viveu? R: ... sofrimento..." você acha que alguma coisa que você passou foi violenta? R: quando eu estava grávida [...] ele quebrou o meu nariz... ele me deu um murro que quebrou o meu nariz, e me colocou para fora de casa com as crianças [...]. E também quando estava grávida [...] ele deu um chute na minha barriga e eu perdi a criança. P: tudo isso você acha que é violência... R: ahá... é violência... (Rosa)

A gravidez aumenta a vulnerabilidade das mulheres para sofrerem violência, principalmente a violência perpetrada pelo parceiro íntimo ${ }^{(13)}$. Estudos ${ }^{(14-15)}$ acerca da temática trazem que a prevalência de violência em mulheres grávidas varia entre $7,4 \%$ e $24,3 \%$, sendo mais frequente a violência psicológica.

Das 5 mulheres, 3 relataram que as situações violentas tiveram início assim que passaram a morar junto de seus parceiros. Uma das mulheres referiu que os episódios de violência apareceram logo nos 3 primeiros meses de vida conjugal, e somente 1 das mulheres comentou que os conflitos tiveram início após 19 anos de casamento. As mulheres narraram que as experiências com seus companheiros sempre foram conturbadas:

[...] logo quando vim morar com ele eu não sabia que morava com mais gente, aí começou tudo. Ele... ele recebia ligações de mulheres chamando para dormir mais ele, ficava bêbado todos os dias [...]. Aí veio me agredir, tentar rasgar a minha roupa, assim que eu cheguei do serviço. P: depois de quanto tempo que vocês estavam juntos? R: depois de uns 6 meses. (Tulipa)

P: depois de quanto tempo ele começou a bater em você? R:... acho que depois de uns três meses que fui morar com ele [...] R: é, era um santo quando só namorava com ele... (Rosa)

... com 2 anos de convivência [...] eu já percebi todo aquele ciúmes. (Hortênsia)

Em estudo sobre as Rotas Críticas, as mulheres entrevistadas também relataram que as agressões perpetradas pelo companheiro começaram com a con- vivência, o casamento e o início das relações sexuais ${ }^{(6)}$. A violência de gênero se mantém sob a condição de desigualdade e pela tentativa de controle e dominação dos homens para com as mulheres, descrita como "assimetria numa relação hierárquica com fins de dominação, de exploração e de opressão. Isto é, a conversão dos diferentes em desiguais e a desigualdade em relação entre superior e inferior. Em segundo lugar, como a ação que trata um ser humano não como um sujeito, mas como uma coisa"(16:33).

No processo de enfrentamento da violência, existem dificuldades relatadas pelas mulheres, como a preocupação das mulheres com os filhos, que é citada por 3 delas como o principal motivo para permanecerem no relacionamento, por medo de perderem a guarda dos filhos para o parceiro, ou não terem como prover o sustento necessário.

Mas o pior de tudo quando os outros falavam para separar dele eu ficava com raiva da pessoa, em vez de ficar bem, ficava com raiva, porque eu falava: vou me separar, quem vai me sustentar, quem vai sustentar as crianças... (Rosa)

Quando descobri a vida dessa pessoa eu estava envolvida, já estava com filho, simplesmente [...] não tinha mais para onde correr, pegar e sair grávida daqui. (Margarida)

Porque o meu maior medo é ele chegar para me fazer um mal para mim [...], deixar os meus filhos abandonados. Arrumar outra pessoa má para bater, judiar... matar meus filhos. (Tulipa)

A condição econômica pode influenciar a saída ou permanência das mulheres na relação com o parceiro agressor, de acordo com a literatura ${ }^{(17)}$ que afirma que mulheres com maior dependência econômica apresentam menores índices de rompimento com o parceiro agressor. A instabilidade econômica e a falta de recursos materiais condicionam as decisões das mulheres; além da preocupação com o bem estar dos filhos e o seu sustento ${ }^{(6)}$.

Outras questões se colocam como barreiras para a superação da violência são os sentimentos de medo e vergonha citados pelas mulheres, sentimentos que as isolam e dificultam a busca por ajuda ${ }^{(18)}$. Segundo informações da pesquisa do Data Senado, o medo (74\%) foi a principal barreira para a superação da violência, seguido da dependência financeira (34\%) e a presença dos filhos $(34 \%)^{(19)}$.

Rosa havia se separado do companheiro há 2 meses e ainda estava se sentido muito mal com tudo o que havia passado e referiu se sentir sozinha, sem apoio. Sua experiência com a igreja que frequentava foi muito ruim, pois foi julgada, condição que alimentava a sua culpa: 
... então, ia na igreja. E como a igreja eles ensinam que a gente tem que ser submissa ao marido, né, tem que aguentar. E quando larguei dele as irmãs me abandonaram, começaram a me julgar. Aí eu parei de ir para a igreja. Falavam que era para eu tratar ele bem... assim... ele podia me maltratar, e eu não podia maltratar ele... entendeu? Tinha épocas que até conseguia, mas não dava!... que que tava passando, não era com elas, era eu... Elas vinham orar direto na minha casa!, elas sabiam da situação. Só que elas só me julgavam assim... - ah, mas tenha paciência, tenha paciência. Jesus mudou meu quadro, ele sabe de toda a situação -, mas cada um sabe onde o calo dói, onde o sapato aperta. Agora estou indo em um espiritismo, lá eu me achei, me encontrei. Lá ninguém julga ninguém, aceita todo mundo, não falam mal de outras religiões... lá me achei. (Rosa)

No caso de Rosa, a instituição religiosa não deu o suporte esperado, e pelo contrário, a fez se sentir responsável pela violência sofrida, como se ela estivesse contrariando os preceitos religiosos de não honrar o casamento. Apesar dessa fala, Sagot ${ }^{(6)}$ refere que algumas instituições religiosas se mostram como apoio por estarem próximas das mulheres e, muitas vezes, oferecem orientação e suporte, mesmo que as instituições não resolvam seus problemas.

A família foi buscada por 4 das 5 das mulheres desse estudo, porém, nem todas tiveram o amparo esperado:

P: a sua família não ficou sabendo...R: a minha mãe ficou. P: e o que ela falava? R: ah, minha mãe falou - volta para casa... ela apoiou. (Tulipa)

P: alguém da sua família sabia de tudo? R: a minha mãe... ela falava para mim separar dele... mas que também eu não tinha coragem. Ela ficou tão feliz depois que eu separei dele... P: mais alguém além da sua mãe sabia? R: só a minha família assim mesmo... $P:$ e o que eles falavam para você? R: a minha família édesse jeito... um não se intromete na vida dos outros não, para falar verdade. Pode ver o circo pegar fogo, que não estão nem aí...P: [...] Você se sentia apoiada por eles? R: não, me sentia sozinha. P: mesmo com a sua mãe falando para você separar...R: Ela falava mas não vinha assim com uma atitude [...] Um dia fui morar na casa dela e - você tem 30 dias para sair daqui... estou te dando um mês, quero que você arrume uma casa -, eu fiquei 15 dias ali e precisei ir embora. (Rosa)

A família de Rosa ofereceu apoio, porém, não tinha como acolher a ela e seus 3 filhos por muito tempo.
Essa oferta não a ajudaria, já que o seu maior desejo era a retirada de seu companheiro de casa, mas, por medo, as pessoas não tentavam se aproximar de seu companheiro.

As 5 mulheres desse estudo buscaram ajuda em serviços da rede formal, com destaque para a UBS e para a DDM. O serviço de saúde é apontado como acolhedor e, aparentemente, as mulheres tinham por expectativa o alívio de suas queixas resultantes da violência, e não necessariamente a resolução direta da situação de violência que vivenciavam ${ }^{(20)}$.

Elas não se preocupam só com a sua saúde...assim... só quando você está doente. Elas se preocupam com a sua pessoa, como você está vivendo, elas se preocuparam bastante comigo. Queriam me ver bem de qualquer jeito. (Rosa)

Sempre que eu [...] passo no médico, o médico conversa comigo... muito atencioso assim, conversar com a pessoa, dar uma explicação né? Uma força [...] uma tranquilidade. (Orquídea)

"Bem [...] porque eles não me trataram com indiferença [...] porque eles viram que eu estava com problema. Porque quando a gente procura um serviço eles acham que a gente está de brincadeira, está com invenção na cabeça. P: E você achou que eles não fizeram isso... R: Não. Ajudou bastante. (Tulipa)

Por meio da fala das mulheres, a violência parece ser uma responsabilidade dos profissionais e do serviço, e a escuta ativa para com elas se mostrou positivo pois as três se sentiram cuidadas. $\mathrm{O}$ acolhimento sem julgamento das mulheres em situação de violência, se mostra como um dos pontos positivos para apoiar as mulheres no enfrentamento da violência, como referido por Schraiber, d'Oliveira, $2002^{(9)}$, de que as mulheres precisam saber que os profissionais se importam com elas e com a ocorrência dessas situações, como ofereçam suporte a partir da construção conjunta de caminhos para superar o problema.

\section{Respostas dos serviços da APS às mulheres}

As mulheres da pesquisa reconhecem os serviços de APS como locais para acolherem acolhedores para com os seus sofrimentos e buscam suporte para as suas queixas decorrentes da violência sofrida, tais como as dores, insônia, dores pelo corpo, dor no peito, insônia, depressão e pressão alta, queixas que estão descritas na literatura ${ }^{(20)}$.

Hortênsia relaciona as suas dores com a violência 
que sofre, o que foi percebido pela profissional, que logo ofereceu suporte:

Eu vim no posto de saúde, né... eu vim mesmo quando não estava aguentando mais... virou uma... uma dor... doía o corpo todo.[...] O primeiro dia que eu vim conversar com a psicóloga... ela já percebeu...eu fui e contei logo o que estava acontecendo... eu não estava bem, comecei a chorar [...] aí começaram a me ajudar. (Hortênsia)

Assim como o caso de Hortênsia, as mulheres chegam aos serviços de saúde com diversas queixas, e os profissionais, a partir da responsabilidade assistencial em violência, como o conhecimento de que a violência está relacionada há uma série de sinais e sintomas, acolhem as mulheres e, a partir da escuta sem julgamento, contribui para que as mulheres falem da violência sofrida, como relatado também por Margarida e Tulipa:

Ficou sabendo através do médico [...] eu estava grávida [...] eles começaram a puxar, a fazer exames, fazer consultas. O médico começou a se envolver e a fazer perguntas... (Margarida)

P: E o que eles falam para você durante a consulta você acha que te ajuda, que não te ajuda, como você vê isso? R: ajuda. Por que te ajuda? R: porque eu me sinto mais confiante. De tomar um rumo. (Tulipa)

A agente de saúde ia em casa e sabia dos meus problemas [...] P: e ela te ajudava... como que era? R: ah, conversando, né. Elas não se preocupam só com a sua saúde... assim... só quando você está doente. Elas se preocupam com a sua pessoa, como você está vivendo, elas se preocuparam bastante comigo. Queriam me ver bem de qualquer jeito. (Rosa)

As mulheres confiam nos profissionais que as atenderam e esse bom relacionamento, baseado no vínculo e na confiança, parece ter se mostrado como um facilitador para dar visibilidade à violência, como na oferta de apoio e referenciamento dos casos, de acordo com a necessidade, superando a lógica da medicalização da violência ${ }^{(3)}$.

A atuação do Agente Comunitário de Saúde (ACS) se destaca, pois é para eles que as mulheres falam dos sofrimentos de casa, ou os vizinhos comentam sobre alguma situação de violência na comunidade e então, o trabalho dos ACS deveria ser orientar em direitos, orientar sobre a rede, e dialogar com a equipe para a oferta de suporte, porém, essa assistência exige treinamento, conhecimento e mapeamento da rede, como a construção conjunta com as mulheres de caminhos assistenciais $^{(21)}$.

\section{Conclusão}

A violência é um grave problema de saúde pública e, aos poucos, tem sido identificada e acolhida pelos profissionais de saúde como parte da responsabilidade assistencial da saúde e da Atenção Primária à Saúde. A UBS foi a primeira instituição buscada por elas para falarem dos problemas decorrentes da violência, ainda que não tenham aparecido inicialmente como violência e, com o apoio dos profissionais, narraram e nominaram como violência. É necessário que os serviços de APS percebam a sua fundamental atuação em reconhecer contextos de violência e apoiar as escolhas das mulheres, fortalecendo-as para que superem a violência a partir, principalmente do trabalho em rede, que esteve ausente nas narrativas das mulheres, e, portanto, ausente como parte da assistência em violência nas UBS, já que a violência é um problema social e para a sua superação exige a participação de diferentes setores assistenciais. Nesse sentido, aparentemente, a Rota ainda se mantém crítica, pois ainda há barreiras importantes que dificultam o percurso das mulheres dentre os serviços da rede, apesar do avanço das políticas públicas em reconhecer a violência como um grave problema para a vida das mulheres.

\section{Referências}

1. Scott J. Gênero: uma categoria útil para análise histórica. [online]. Trad. Christine Rufino Dabat e Maria Betânia Ávila. 1990. Disponível em: https://edisciplinas.usp.br/pluginfile. php/1840746/mod_resource/content /0/G\%C3\%AAnero-Joan\%20Scott.pdf (2 dez 2016)

2. Ellsberg M, Jansen HA, Heise L, Watts CH, Garcia-Moreno C, WHO Multi-country Study on Women's Health and Domestic Violence against Women Study Team. Intimate partner violence ad women's physical and mental health in the WHO multi-country study on women's health and domestic violence: an observational study. Lancet. 2008; 371(9619):1165-72.

3. Brasil. Presidência da República. Secretaria Nacional de Enfrentamento à Violência contra as Mulheres. Secretaria de Políticas para as Mulheres. Política nacional de enfrentamento à violência contra as mulheres. Brasília (DF): Secretaria de Políticas para as Mulheres; 2011. 45p.

4. Starfield B. Atenção primária: equilíbrio entre necessidades de saúde, serviços e tecnologia. Brasília (DF): UNESCO; 2002. 726p.

5. D'Oliveira AFPL, Schraiber LB, Hanada H, Durand J. Atenção integral à saúde de mulheres em situação de violência de gênero: uma alternativa para a atenção primária em saúde. Ciênc Saúde Coletiva. 2009; 14(4):1037-50.

6. Sagot M. La Ruta crítica de las mujeres afectadas por la violencia intrafamiliar en America Latina: estudios de caso de diez países. Washington, DC: Organización Panamericana de La Salud; 2000. $181 \mathrm{p}$.

7. Meneghel SN, Bairros F, Mueller B, Monteiro D, Oliveira LP, Collaziol ME. Rotas críticas de mulheres em situação de violência: depoimentos de mulheres e operadores em Porto Alegre, Rio 
Grande do Sul, Brasil. Cad Saúde Pública. 2011; 27(4):743-52.

8. Bardin L. Análise de conteúdo. Lisboa: Edições 70; 1977. 226p.

9. Schraiber LB, D’Oliveira AFPL. O que devem saber os profissionais de saúde para promover os direitos e a saúde das mulheres em situação de violência doméstica. São Paulo: Coletivo Feminista Sexualidade e Saúde; 2002. 36p.

10. Schraiber L, D'Oliveira AF, Hanada H, Figueiredo W, Couto M, Kiss L, et al. Violência vivida: a dor que não tem nome. Interface Comun Saúde Educ. 2003; 7(12):41-54.

11. Silva LL, Coelho EBS, Caponi SNC. Violência silenciosa: violência psicológica como condição da violência física doméstica. Interface Comun Saúde Educ. 2007;11(21):93-103.

12. Schraiber LB, D'Oliveira AFPL, Falcão MTC, Figueiredo WS. Violência dói e não é direito: a violência contra a mulher, a saúde e os direitos humanos. São Paulo: UNESP; 2005. 183p.

13. Audi CAF, Segall-Corrêa AM, Santiago SM, Andrade MGG, Pérez-Escamilla R. Violência doméstica na gravidez: prevalência e fatores associados. Rev Saúde Pública. 2008; 42(5):877-85.

14. Santos SA, Lovisi GM, Valente CCB, Legay L, Abelha L. Violência doméstica durante a gestação: um estudo descritivo em uma unidade básica de saúde no Rio de Janeiro. Cad Saúde Colet. (RJ.). 2010;18(4):483-93.

15. Menezes TC, Amorim MMR, Santos LC, Faúndes A. Violência física doméstica e gestação: resultados de um inquérito no puerpério. Rev Bras Ginecol Obstet. 2003; 25(5):309-16.

16. Chauí M. Participando do debate sobre mulher e violência. In:
Chauí M, Cardoso R, Paoli MC. Perspectivas antropológicas da mulher: sobre mulher e violência. Rio de Janeiro: Zahar; 1985. v.4, p. 25-62.

17. Kim J, Gray KA. Leave or stay? Battered women's decision after intimate partner violence. J Interpers Violence. 2008; 23(10):146582.

18. Terra MF, D'Oliveira AFPL, Schraiber LB. Medo e vergonha como barreiras para superar a violência doméstica de gênero. Athenea Digital. [periódico online] 2015; [citado 2 dez 2016]; 15(3):109-25. Disponível em: http:/ /atheneadigital.net/article/ view/v15-n3-terra-doliveira-schraiber/1538-pdf-pt

19. Brasil. Senado Federal. Secretaria de Transparência. Coordenação de Controle Social. Serviço de Pesquisa DataSenado. Violência doméstica e familiar contra a mulher. [online]. Brasília (DF): Senado Federal; 2015. 81p. Disponível em: https://www12. senado.gov.br/noticias/arquivos/2015/08/10/violencia-domestica-e-familiar-contra-a-mulher (2 dez 2016)

20. Schraiber LB, D'Oliveira AFLP. Violência contra mulheres: interfaces com a saúde. Interface Comun Saúde Educ.1999; 3(5):11-26.

21. Silva JA, Dalmaso ASW. Agente comunitário de saúde: o ser, o saber, o fazer. Rio de Janeiro: Fiocruz; 2002. 240p.

Trabalho recebido: 07/07/2017

Trabalho aprovado: $21 / 03 / 2018$ 